\title{
O SEGREDO DO “PRÍNCIPE CONSTANTE”
}

\section{The secret of "Constant Prince"}

\author{
Franco Ruffini \\ Università degli Studi Roma Tre
}

Ricardo Gomes
tradução

Resumo: Por meio de pesquisa histórica e bibliográfica, o artigo procura revelar o segredo do trabalho desenvolvido em isolamento por Jerzy Grotowski e Ryszard Cieślak, durante a preparação do espetáculo do Teatro Laboratório, O Príncipe Constante. $\mathrm{O}$ autor investiga o papel decisivo e revolucionário deste processo de trabalho e seus desdobramentos na trajetória artística e pessoal de Grotowski, Cieślak e do Teatro Laboratório, referências fundamentais para o teatro do século XX.

Palavras-chave: Jerzy Grotowski; Ryszard Cieślak; Príncipe Constante.

Abstract: Through historical and bibliographic research, the article seeks to reveal the secret of the work developed in isolation by Jerzy Grotowski and Ryszard Cieślak during the preparation of the Laboratory Theatre's performance The Constant Prince. The author investigates the decisive and revolutionary role of this work process and its consequences in the artistic and personal trajectory of Grotowski, Cieślak and Laboratory Theatre, fundamental references for 20th century theater.

Keywords: Jerzy Grotowski; Ryszard Cieślak; The Constant Prince. 
A propósito do trabalho entre Grotowski e Cieślak para O Príncipe constante, Zbigniew Osiński (2011, p. 240) afirma que "a parte mais importante [...] permanecerá um segredo deles para sempre. E assim deve ser, uma vez que esta experiência é, pela sua natureza, intraduzivel em palavras". Sei muito bem que a afirmação de Osiński deve ser lida como um sinal de respeito em relação a Grotowski e Cieślak e não como uma intimidação aos pesquisadores; entretanto, minha opinião é diversa. Se podemos nos render ao mistério, ou ao segredo, não podemos pressupo-lo, eximindo-nos, deste modo, da tarefa de tentar revelá-lo. Que é, podemos dizer, a missão do pesquisador.

\section{Primeira metade da viagem. 0 "o que"}

Se cumprimento da missão soa retórico, o que segue poderá ser lido como a prestação de contas, passo a passo, do trabalho realizado para enfrentá-la. E concluí-la com sucesso.

\section{O Príncipe constante}

Depois da expedição falida para liberar a cidade de Ceuta do assédio dos Mouros, Don Fernando, príncipe de Portugal, é entregue como refém ao rei de Fez, como garantia de um acordo em base, ao qual Portugal se compromete a devolver a cidade conquistada alguns anos antes. A liberdade do prisioneiro em troca de Ceuta. No início, Don Fernando é tratado com todo o respeito devido a um igual. Mas, será ele mesmo a romper o acordo, considerando um sacrilégio a restituição de uma cidade cristã aos infiéis. Em um longo e apaixonado monólogo, se proclama "príncipe constante", entregando-se, deste modo, ao seu paradoxal destino de mártir. Enquanto é, contra sua vontade, mercadoria de troca, não pode ser morto, pois nesse caso não seria mais mercadoria, mas deve ser forçado, ou melhor, torturado, para que consinta a troca. A partir do momento da proclamação, torna-se um prisioneiro qualquer. $\mathrm{E}$ ainda mais: um escravo 
rebelde, que recusa obediência ao próprio soberano. Acorrentado no pescoço e nos pés, é obrigado a trabalhar no jardim e nas latrinas. Nutrido com pão e água, esfarrapado, imundo, todavia recusa-se a mendigar em nome de Alá, assim como se recusa a fugir. Em uma apoteose final, consumará sua morte de "príncipe constante" na sua fé. Às vicissitudes de Don Fernando se entrelaça a conturbada história de amor entre Muley, guerreiro mouro, e a princesa Fenice.

O texto de Calderón remonta a 1629; Juliusz Słowacki o traduziu em 1844, depois de ter aprendido o espanhol com esse objetivo, evidenciando o quanto considerava-o importante para a cultura e a missão histórica polonesa. Grotowski interviu sobre o texto de maneira decisiva, mas não a ponto de alterar o seu desenvolvimento. O espetáculo estreou em 25 de abril de 1965 e se tornou - com as apresentações ao Festival do Théâtre des Nations, em Paris, entre 21 e 25 de junho de 1966 - um triunfo internacional ${ }^{1}$.

Os ensaios com todo o grupo iniciaram-se na metade de 64, mas um ano antes já haviam começado somente com Cieślak. O trabalho de preparação se desenvolveu, de fato, de uma maneira insólita em relação à práxis do Teatro Laboratório. Grotowski não trabalhou com todos os atores contemporaneamente. Foi antes, escrevera, "um trabalho com dois grupos, dos quais um dos grupos era uma pessoa, Ryszard [Cieślak], e o outro grupo os outros atores" (GROTOWSKI, 1992, p. 19). O trabalho com o "grupo Cieślak" se desenvolvia em modo e em lugar apartados, sem que o outro grupo conhecesse a sua natureza. Além disso, ainda nas palavras de Grotowski (Ibidem, p. 16-17), enquanto

o texto fala de um mártir que recusa a submeter-se a leis que não aceita [...] no trabalho do diretor com Ryszard Cieślak nunca tocamos em nada que fosse triste. Todo o papel foi fundado sobre o tempo muito preciso da sua memória [...] relacionada ao período em que era adolescente, quando teve sua primeira grande, enorme experiência amorosa.

\footnotetext{
${ }^{1}$ Cf. Nas Referências Bibliográficas, outros estudos monográficos sobre o Príncipe constante: o texto pioneiro de Serge Ouakine (1970) e o livro de Lorenzo Mango (2008).
} 
Somente quando o papel foi fixado em todos os mínimos detalhes, começou-se a inseri-lo no contexto das ações, cenas e textos do grupo plural, de modo a garantir a sua coerência dramatúrgica. Ou seja, de modo que, naquela revivescência amorosa, o espectador pudesse ver ações que se referissem a um mártir em nome da fé.

A singularidade de um procedimento como aquele, o papel de Cieślak, que parece ser totalmente estranho ao personagem de Don Fernando, fizeram do Príncipe constante um caso único que, graças ao sucesso internacional do espetáculo, terminou por absorver toda a história de Grotowski enquanto diretor. E "prece carnal" - a fórmula introduzida para definir o primeiro encontro com o amor, em toda a sua força dos sentidos e além dos sentidos - fez o resto. $O$ trabalho para o Príncipe constante tornou-se um segredo sobre o qual, segundo Osiński, não se deve falar.

\section{Cartas a Eugenio Barba}

Por paradoxo, o primeiro a transgredir a proibição foi o próprio Grotowski. Diretamente ou menos, o Príncipe constante está no centro de quase todas as cartas que envia a Eugenio Barba, desde a de 15 de setembro de 1963, quando Barba acaba de partir para a Índia, até a de 26 de abril de 1965, quando, tendo retornado da Índia, Barba já havia partido definitivamente para a aventura do Odin Teatret na Noruega, iniciada em outubro de $1964^{2}$. Na data da primeira carta, como afirma Grotowski, o trabalho secreto - aquele somente com Cieślak - havia iniciado a pouco, e, na data da última, o espetáculo havia estreado no dia anterior.

Mais que de mistério ou segredo, Grotowski fala da virada radical, uma verdadeira revolução, representada pelo Príncipe constante. Recapitula, como prestação de contas, em 26 de abril de 1965:

\footnotetext{
${ }^{2}$ Trata-se das cartas 2 a 15, dentre as 26 cartas de Grotowski a Barba, publicadas em apêndice ao livro de Eugenio Barba (1998), La terra di cenere e diamanti: il mio apprendistato in Polonia. O livro foi publicado no Brasil com o título: A terra de cinza e diamantes: o meu aprendizado na Polônia.
} 
Desde já, duas coisas são evidentes. Primeiro: [O Príncipe constante] marca o início de um novo período na estética da nossa "firma". Segundo: esse espetáculo representa a tentativa de aplicar as pesquisas de fronteira entre tantra e teatro, de que Ihe falei tempos atrás. Isto exige uma extrema precisão técnica, especialmente em relação à técnica espiritual do ator; tudo está suspenso por um fio, e pode facilmente perder a direção [...] Porque existe a possibilidade que este tipo de trabalho possa se desenvolver. Seja do ponto de vista do método do ator que daquilo que poderia ser definido o espírito da obra, considero a experiência artística mais importante que eu tenha realizado até agora. E não só artística. (GROTOWSKI apud BARBA, 1998, p. 175-176)

Marcando a projeção para um futuro além da arte, Grotowski apenas reafirmava o que havia escrito na abertura da correspondência, em 21 de setembro de 1963, quando o espetáculo que estava oficialmente sendo ensaiado era Estudo sobre Hamlet:

De resto, fiz uma reforma radical nos exercícios [...] Creio que as pesquisas deste último período (auto-exploração, anatomia psíquica, pisico-análise do "não privado"), se desenvolvidas, possam abrir inesgotáveis possibilidades e perspectivas. Mesmo neste estágio, posso afirmar que o "patanjali do teatro" (método), neste caminho, é tangível e verificável. (Ibidem, p. 146-147) ${ }^{3}$

\section{A revolução do Príncipe constante continuará a ser o motivo central.} "Estranhas experiências - escreve em $1^{\circ}$ de setembro de 1964 - mudei os exercícios e, se devo ser sincero, revi todo o método" (Ibidem, p. 157), e ressalta

${ }^{3}$ Estudo sobre Hamlet estreará em 17 de março de 1964. Fará pouquíssimas apresentações, mas Grotowski o considerava fundamental para a sua pesquisa sobre o ator, uma espécie de laboratório para a revolução in pectore do Príncipe constante. Sobre o espetáculo, cf. "Amleto" nel laboratorio teatrale (FLASZEN, 2001a); e sobretudo o parágrafo Amleto senza amici, no livro La terra di cenere e diamanti (BARBA, 1998, p. 91-99). É o caso de tentar desatar o nó do ano de trabalho em segredo entre Grotowski e Cieślak. Grotowski o coloca entre 1963 e a primeira metade de 1964. As suas declarações são uma prova irrefutável, pelo menos até que apareça uma prova em contrário de peso igual. Vale a pena, em todo caso, confrontar-se com os fatos. Fora o trabalho para Estudo sobre Hamlet, nos primeiros meses de 64, Grotowski teve que enfrentar o problema do temor de que seu teatro fosse fechado. Tinha outras coisas sobre as quais pensar - além de Hamlet e disputas políticas, a que se reduziria o suposto ano? Resta a possibilidade que: primeiro, os ensaios de Hamlet fossem também um trabalho com e sobre o ator sem a titularidade de um espetáculo, por assim dizer; e segundo, que não apesar, mas exatamente em razão da asfixiante pressão política nos primeiros meses de 64, ao teatro restasse apenas um espaçotempo apartado, no qual aprofundar, cara a cara com um só ator, aquele trabalho de "hipnagogo que mobiliza as reservas espirituais escondidas do ator", no qual Flaszen (2001a, p. 101), em "Amleto" nel laboratorio teatrale, indica a essência do experimento Hamlet. Para a ligação entre Hamlet e Príncipe constante, em particular, cf. De mistério em mistério: algumas observações em abertura (FLASZEN, 2001b, p. 27). 
mais analiticamente em 29 de dezembro: "Do modo de conduzir os ensaios do Príncipe constante até os exercícios, tudo é distante [...] o que não quer dizer uma volta atrás, mas, ao contrário, que enfim estamos resolvendo as questões de método a um nível mais alto" (Ibidem, p. 165-166).

Por trás de um panorama de epifanias e proclamações como aquele, é, porém, difícil encontrar indicações concretas sobre o "desenvolvimento do método", que é a chave da mudança do processo, mas é evocado somente por contraste. Grotowski o nomina explicitamente em uma carta de 5 de abril de 1965. Falando do livro de Barba, Alla ricerca del teatro perduto (Em busca do teatro perdido), auspicia a sua publicação em polonês - que não acontecerá nunca ${ }^{4}$ mas, naquele caso, conclui: "teria que acrescentar um apêndice sobre o desenvolvimento do método de 1964 [data em que o livro tinha sido liberado para a publicação] até hoje" (Ibidem, p. 173, grifo meu).

Se não sabemos ainda no que consistisse, o "desenvolvimento do método", sabemos ainda menos a sua data de início e o seu período de gestação.

\section{O programa do espetáculo}

Enquanto isso, porém, mais dia menos dia, o Príncipe constante chegaria à cena, acompanhado por um "Programa", onde finalmente Grotowski entraria no mérito. Enviou uma cópia a Barba em Oslo, e se informou se ele a recebeu. $\mathrm{O}$ opúsculo se compõe de três contribuições: uma ficha introdutória organizada por Ludwik Flaszen, um resumo, capítulo por capítulo, do livro de Barba, e um denso ensaio teórico, também de Flaszen. A síntese do livro de Barba (publicado na Itália, em fevereiro de 1965) é apresentada como Manual italiano sobre o método do Teatro Laboratório das 13 fileiras - Eugenio Barba: Em busca do teatro perdido. O ensaio de Flaszen - Sobre o método de atuação - foi escrito originalmente, em abril de 64 , como um material crítico para ser usado pela comissão encarregada pela sobrevivência do teatro, e foi depois reelaborado para

\footnotetext{
${ }^{4}$ O livro foi publicado em 1965, na Itália e na Hungria. Não há uma tradução em português (nota do tradutor).
} 
o "Programa". Com a aprovação incondicional de Grotowski, que escreve: "as correções introduzidas no artigo de Flaszen sobre o método do ator correspondem exatamente à minha visão atual do problema" (Ibidem, p. 177).

A partir das orientações de método contidas no livro de Barba, a revolução do Príncipe constante alcançava a "visão atual do problema", ilustrada no ensaio de Flaszen ${ }^{5}$. Do que falava aquele texto?

Depois de passar em revista os vários métodos de atuação, em particular o de Meyerhold, ressaltando as diferenças em relação a Grotowski, Flaszen se detém no confronto com Stanislávski. Será preciso reproduzir por extenso a passagem em questão, porque é ali que se encontra a semente do segredo. A revolução. Ir além de Stanislávski, mas no caminho assinalado por Stanislávski. Ou, como reforça especularmente, continuar a confrontar-se com as perguntas de Stanislávski, mas procurando as próprias respostas.

O método da "identificação emocional" pressupõe a utilização de estratos psíquicos do ator que se integram na psique do personagem representado, colocando o ator nas mesmas circunstâncias: "o que você faria se fosse ele naquela situação?". O ator de Grotowski tem um outro objetivo. Paradoxalmente, representa a si mesmo; a si mesmo como representante da humanidade em sua condição contemporânea [...] Por exemplo, se interpreta um general que morre no campo de batalha, não tenta recriar dentro de si a imagem de um verdadeiro general que morre realmente no fragor da batalha; não se preocupa com aquilo que um general poderia sentir e como poderia se comportar, com a finalidade de re-viver subjetivamente e recriar uma cognição objetiva sobre generais moribundos em algum modo orgânico e crível. Muito pelo contrário: apenas pelo fato de imaginar-se um general moribundo, o ator tenta reencontrar sua própria verdade, algo pessoal e íntimo, com uma curvatura subjetiva. Por exemplo, representa o próprio sonho de morte retórica; o desejo de alguma expressão heróica, a fraqueza humana de idealizar a si

\footnotetext{
${ }^{5}$ Há duas versões deste texto: L'arte dell'attore, em II Teatr Laboratorium di Jerzy Grotowski 1959-1969 (FLASZEN, 2001c) e Sul metodo per l'arte dell'attore, em Grotowski \& Company - Sorgenti e variazioni (FLASZEN, 2014). Cito, a partir desta segunda edição cujo título é mais correspondente ao original polonês, O Metodzie Aktorskiej (nota do tradutor: há disponíveis edições brasileiras de ambos os livros). É - caso de ressaltar que esta contribuição de Flaszen está ausente em Per un teatro povero (GROTOWSKI, 1970), onde o trabalho de Grotowski e Cieślak para o Príncipe constante é relegado a uma "sala fechada" para o leitor. Sobre este tipo de composição do livro, organizado exatamente para manter o "segredo", cf. o meu Per un teatro povero, agora em versão definitiva no livro Grotowski e Gurdjieff (RUFFINI, 2019, p. 185-210).
} 
mesmo em detrimento dos outros; ele exibe as suas fontes gradualmente, quase como se estivesse exibindo um tecido orgânico, e não recua quando a sua intimidade e temas constrangedores estão para ser violados. Na realidade, pelo contrário, leva-os adiante até as extremas consequências, quase como se estivesse literalmente oferecendo a verdade do seu corpo, suas experiências, suas motivações secretas, quase como se as estivesse oferecendo em sacrifício aqui e agora, diante dos olhos dos espectadores, e não na situação imaginária de um campo de batalha. Eis como responde à pergunta: como ser um general sem ser um general? Como morrer na batalha sem combater e sucumbir?. (FLASZEN, 2014, p. 150-151)

Entre o ator que re-vive a agonia de um comandante caído em combate e o mesmo ator que transcende aquela experiência na nostalgia universal de uma morte heróica, para além daquela particular morte em batalha, entre o Stanislávski das ações físicas e o Grotowski além das ações físicas de Stanislávski: exatamente entre estas duas referências, definia-se o trabalho a dois de Grotowski e Cieślak. Dirá: "Quando eu trabalhava com um ator não ficava refletindo nem sobre o 'se' nem sobre as 'circunstâncias dadas' [...] O ator apela para a sua própria vida, não procura no campo da 'memória emotiva' nem do 'se'” (GROTOWSKI, 2016a. p. 240). As "circunstâncias dadas" do Príncipe constante não estavam na sala secreta: estavam fora, confiadas ao contexto representativo do grupo plural. Na sala secreta, o desafio proposto era apenas entre a revivescência amorosa de uma primeira experiência de adolescente e aquela mesma revivescência vivida como "prece carnal", segundo a expressão cunhada por Grotowski.

Carnal porque é do corpo e prece porque está além do corpo: na própria voz que pronuncia a prece e naquela da qual esperamos a resposta ${ }^{6}$.

\section{Dentro e fora da metáfora}

\footnotetext{
${ }^{6}$ Sobre o percurso da simples recordação à revivescência, e desta à superação dela mesma, cf. BARBA, 2009. No capítulo La zona torrida del ricordo (A zona tórrida da lembrança), Barba propõe um itinerário que parte da zona fria dos fatos; passa pela zona húmida das "nossas reações presentes às emoções passadas"; atinge a zona fecunda, na qual "a lembrança não pertence mais àquilo que fomos, não é mais sentimento, mas carne e osso"; para chegar finalmente, às vezes, à zona tórrida, onde "os extremos se abraçam". A superação de Stanislávski, ao longo do seu próprio caminho, poderia se formular como a passagem da zona fecunda à zona tórrida da lembrança.
} 
É o destino das metáforas. Nascem com a função de levar o olhar para o alto, para permitir que se veja além, fora da metáfora. Devem ser atraentes, para dar vontade de subir em cima, mas se são atraentes demais, acabam atraindo o olhar somente para si mesmas. Grotowski foi o primeiro a se dar conta de que havia este tipo de risco na sua "prece carnal". E adiantou-se para remediar o problema, ancorando o voo da metáfora a fatos concretos. Fez isso prontamente, ainda que não imediatamente.

Sobre o trabalho com Cieślak para o Príncipe constante, expressou-se a uma grande distância de tempo, e em três etapas. A chegada é importante, mas o percurso é essencial para que se possa medir a sua importância. A primeira etapa é uma fala de 1990, durante um evento em memória de Cieślak, falecido em junho daquele $a n o^{7}$. A segunda é uma passagem do ensaio Dalla compagnia teatrale all'arte come veicolo, publicado na Itália em 93 como posfácio do livro de Thomas Richards, Al lavoro con Grotowski sulle azioni fisiche ${ }^{8}$; a última é a mesma passagem revista para as edições francesa e inglesa do livro, em $1995^{9}$. Esta revisão foi incorporada na $3^{a}$ edição do livro na Itália, em 2002, e na edição das obras completas de Grotowski, em 2016.

O ponto de partida comum é a revivescência amorosa de Cieślak. No primeiro testemunho - 1990 - Grotowski (1992, p. 17) escreve: "É como se, entre esses dois aspectos [entre corpo e espírito] tivesse se criado uma ponte que é uma prece carnal". O "como se" é significativo. A prece carnal aparece sendo o que é: uma metáfora, veículo para a definição do "como se". No testemunho sucessivo - 1993 -, a fórmula desaparece, substituída por uma paráfrase mais extensa: "no man's land entre a sensualidade e a prece" (GROTOWSKI, 1993, p. 130) - que qualquer um, de sexo masculino, que ainda tenha viva a memória do primeiro encontro com o amor, sabe que não é uma metáfora. "Prece carnal"

\footnotetext{
${ }^{7}$ GROTOWSKI, 1992.

${ }^{8}$ GROTOWSKI, 1993.

${ }^{9}$ A tradução para o português desse livro, intitulada Trabalhando com Grotowski sobre as ações físicas (RICHARDS, 2012), foi realizada a partir da edição inglesa de 1995, logo, o texto em questão, intitulado em português Da companhia teatral à arte como veículo, corresponde ao momento a que Ruffini refere-se como a "última etapa" (nota do tradutor).
} 
reaparece na última etapa, em $1995^{10}$. O trabalho de Cieślak, escreve Grotowski (2016b, p. 82),

\begin{abstract}
estava ligad[o] à nossa leitura - antes mesmo de começar o trabalho - do Cântico espiritual de João da Cruz (que religa-se à tradição bíblica do Cântico dos Cânticos). Nessa referência oculta, a relação entre a alma e o Verdadeiro - ou se preferirem entre Homem e Deus - é a relação da Amada com o Amado. Foi isso que levou Cieślak em direção à lembrança de uma experiência de amor a tal ponto única que se tornava uma prece carnal.
\end{abstract}

A "prece carnal" já existia no primeiro testemunho; agora, aquela ancoragem aos fatos a levava finalmente para fora da metáfora. O Cântico espiritual e João da Cruz: um texto e o seu autor. Mas, por detrás destas duas notícias secas, quase de nota de rodapé, se escancarava um mundo inesperado, no qual, ao final da exploração, João da Cruz e o seu Cântico espiritual se revelarão como os verdadeiros detentores das chaves para penetrar no segredo do Príncipe constante.

\title{
O "Cântico espiritual" de João da Cruz
}

O Cântico espiritual é uma lírica amorosa de 39 estrofes, com um total de 195 versos. Composto entre julho e agosto de 1578, foi publicado postumamente em 1618, acompanhado de comentários minuciosos - explicações redigidas de acordo com a demanda, como veremos - de caráter teológico ${ }^{11}$. Aparece então, e é predominantemente lido assim ainda hoje, como um dos tratados de mística de João da Cruz, junto com Noite escura da alma e Subida ao Monte Carmelo. O

\footnotetext{
${ }^{10}$ A menção ao percurso é para ressaltar que nem tudo se reduz à meta - que inclusive pode ser muito menos interessante que o percurso. É o que acontece, infelizmente, com a recente edição das obras completas de Grotowski, onde os textos são publicados em "versão definitiva", não levando em conta quais foram, eventualmente, a versão inicial e aquelas intermediárias. No nosso caso, a ancoragem da "prece carnal" ao Cântico espiritual e a João da Cruz aparece já na "versão definitiva" do testemunho de 1990 (GROTOWSKI, 2016c), mas estava ausente na "versão inicial" (GROTOWSKI, 1992). O percurso simplesmente desaparece; e com ele desaparece a gênese - a vida - da "prece carnal" que é a sua protagonista.

${ }_{11}$ Para a biografia e as obras de João da Cruz, a referência é Vida y obras de San Juan de la Cruz (DE JESUS O. C. D.; DEL NIÑO JESUS O. C. D.; RUANO O. C. D., 1978).
} 
formato editorial justifica esta perspectiva de leitura. Na origem, porém, o Cântico espiritual era algo muito diferente de um tratado de mística e, a rigor, muito diferente também de um diálogo de amor entre esposo e esposa, como se pode ler depois de pronto. Mas, são exatamente os acontecimentos durante a redação da obra a definir a identidade profunda do Cântico espiritual. Para além dos gêneros poéticos e formatos editoriais, foi esta identidade profunda que entrou na sala do trabalho a dois de Cieślak e Grotowski.

O autor, cujo nome de batismo é Juan de Yepes, nasce em 1542, filho de um nobre deserdado e de uma humilde tecelã, Catalina Alvarez. Desde cedo órfão de pai, desloca-se com sua mãe de cidade em cidade, vivendo na pobreza. Seus estudos, esporádicos e aventurosos, serão completados entre 64 e 68, na Universidade de Salamanca. Em 1563, entra para a ordem dos carmelitas, na qual, junto a Tereza d'Ávila, que encontrou em 1567, promoverá uma radical reforma, de "calçados" a "descalços". Funda mosteiros e, por alguns anos - de 72 a 77 -, desenvolve a atividade de padre espiritual no mosteiro da Incarnação, em Ávila. A radicalidade eversiva da reforma e a sua intransigência pessoal ao praticá-la logo tornam-no mal visto pelas autoridades oficiais da Ordem - na época dos calçados -, até que, acusado em base a um pretexto, é preso, em 2 de dezembro de 1577.

Conduzido diante de um tribunal, no convento dos calçados de Toledo, é submetido a um processo sumário, durante o qual se mantém inabalável em suas posições. Continua a declarar-se inocente da acusação de fachada e, sobretudo, daquela de fundo, que estava na raiz da acusação. Resiste a todo tipo de pressão psicológica, à imputação do pecado de orgulho, às ameaças e até à promessa de um cargo de padre superior, acompanhada por um crucifixo de ouro de grande valor. "Aquele que busca por Cristo nu - é a sua resposta - não precisa de joias de ouro". Declarado rebelde e contumaz, é condenado à prisão por tempo indeterminado, ou seja, por todo o tempo que parecer necessário ao poder superior da Ordem. É aprisionado no convento e, algumas semanas depois, transferido para uma cela especialmente predisposta para a sua custódia. 
Começa o período do martírio, que se prolongará até a metade de agosto de 1578, durante seis terríveis meses, do gélido inverno ao tórrido verão de Toledo. A cela é um buraco escuro e fétido, sem janelas. No chão de tábuas, apenas duas cobertas velhas. Despido até mesmo do capuz e do escapulário, deixa-se com ele apenas o breviário. Passa os dias praticamente no escuro, rodeado de seus excrementos, sendo devorado por insetos e parasitas, alimentado com pão, água e, somente de vez em quando, algumas sardinhas. Três vezes por semana - às segundas, quartas e sextas - é conduzido ao refeitório para receber a chamada "punição circular". Ajoelhado no chão, consome a sua parca refeição diante dos irmãos que comem, enquanto um prelado contesta o seu obstinado pecado de orgulho, dispensando - ao final da prédica a primeira parte da punição. Com os ombros descobertos, Juan é espancado com uma verga. Depois do primeiro, todos os outros confrades se revezam para completar o "círculo".

Depois de quase seis meses desse tratamento, o carcereiro é substituído por um novo confrade que, movido pela piedade, Ihe dá uma túnica e, sobretudo, papel e pena. Quando este, porém, Ihe sussurra que poderia evitar que recebesse a dose semanal de pancadas, tem como resposta que ele não quer se privar de sua merecida punição. Tendo tudo o que é necessário, Juan se põe a escrever o Cântico espiritual.

Uma tal abundância de detalhes serve para consentir um confronto não genérico entre o calvário de João da Cruz e o de seu duplo no teatro, Don Fernando "príncipe constante". A Don Fernando é imputado o pecado de orgulho, enquanto escravo que recusa obediência ao senhor. O senhor de João da Cruz era o padre superior da Ordem, assim como o rei de Fez era o de Don Fernando. Também a Don Fernando se fazem promessas. E sobretudo, para ambos, impressiona a insistência na falta de comida, na degradação física e na sujeira. A princesa Fenice diz que não consegue suportar o fedor daquele mártir que está diante dela, por quem, contudo, sente piedade.

João da Cruz é a encarnação da história do personagem de Calderón. Nada mais natural que Grotowski e Cieślak decidissem assumi-lo como modelo ou, de 
qualquer modo, como referência com a qual confrontar-se. Neste sentido, o testemunho de Grotowski ainda corre o risco de desviar-nos do caminho certo. Como se o Cântico espiritual por si só, na sua identidade de obra, fosse a causa primeira do trabalho com Cieślak; como se antes do Cântico não existisse João da Cruz, e como se, bem antes que como autor daquela lírica, João da Cruz não existisse como mártir em nome da fé. Mas antes e depois, aqui, tem bem pouco sentido. Seria melhor dizer "inextricavelmente juntos", de tão entrelaçados que estão, de fato, um no outro.

Bastaria a biografia, e no entanto não é só uma questão de circunstâncias biográficas. Tem mais, entre o Cântico espiritual e João da Cruz, bem mais.

\section{Quem escreveu o "Cântico espiritual"?}

Assim o deixamos, entre julho e agosto de 1578, na sua cela abrasada pelo calor de agosto. Com as costas ensanguentadas pelos golpes, aos quais, mesmo podendo, não quis se furtar, reduzido a pouco mais que um esqueleto, João da Cruz escreve o Cântico espiritual. Ele fez isso, não há mais nada a dizer. Por contraste, vale a pena ver o que ele não fez.

Finalmente com uma arma na mão, João da Cruz não escreve uma mensagem a ser entregue clandestinamente a algum protetor externo em condições de interceder por ele. Não coloca no papel suas últimas vontades, nem escreve um ato de acusação, para futura memória, contra seus perseguidores, não dá voz a um amargo lamento ou invocação a Deus para ter conforto, pelo menos, se não ajuda... Não fez nada disso. O que fez foi escrever uma lírica de amor. Não, com certeza, para entrar no rol dos escritores do gênero, mas como se aqueles versos sensuais, apaixonados, transbordantes de eros - onde sem aparecer, Cristo-Deus transparece na desmedida de um amor carnal - fossem a reação orgânica, necessária, verdadeira, para dar, muito além de todo o tormento sofrido, testemunho pleno e extremo da sua constância na fé. Ele é o autor, certamente, mas quem escreveu o Cântico espiritual? 
É a esta pergunta que João da Cruz respondeu implicitamente, travestindo - Cântico como um tratado de mística: um volume com um número de páginas vinte vezes maior que o do texto da poesia. Talvez com a cumplicidade de seu novo carcereiro, Juan consegue escapar de sua cela, na noite de 17 de agosto de 1578. Com várias vicissitudes, retoma a atividade de poeta, teólogo e mestre de fé, até 1591, ano de sua morte, já em universal odor de santidade. Em 1584, depois de ter completado o Cântico com os poucos versos que faltavam, compõe um longo, analítico e erudito comentário teológico sobre ele, estrofe por estrofe e, dentro de cada uma, verso por verso, assim como foi pedido por madre Anna de Jesus, madre superiora das descalças de São José, em Granada. Explicações declaraciones - mais que comentários, havia precisado a madre superiora. Juan obedece, mesmo declarando, num breve prólogo, que não havia nada para explicar e que esta, de fato, não podia ser a sua intenção. Aqueles versos, explicou - isto sim ele podia explicar - foram ditados por Deus. Ele, João da Cruz, havia apenas emprestado papel e pena, um pouco de técnica de versificação e algum eco de memória do Cântico dos Cânticos de Salomão. A sabedoria do amor, concluiu, "age como a fé, por meio da qual amamos Deus sem compreendê-lo".

Mas, existe uma física por detrás, ou ao menos junto, da metafísica que está além dele. Naquele Cântico espiritual, feito sob ditado divino, qual foi o papel das condições físicas da pessoa terrena que o escreveu? Corpo e espírito são distintos, não são separados. Deixando a metafísica de lado, o que acontece quando um corpo é levado ao limite extremo da resistência? Se não chega ao colapso, os esportistas falam da experiência de um "segundo fôlego", no qual o corpo descobre energias desconhecidas. Não um inesperado resíduo, mas uma nova forma de energia que se manifesta no corpo, mas obviamente não é só do corpo.

Seja como for que a chamemos, é a João da Cruz, naquelas condições, que o espírito divino ditou os versos do Cântico espiritual. A escrevê-los foi, de qualquer modo, um homem novo, renascido de si mesmo: um outro João da Cruz. 


\section{A outra metade da viagem. 0 "como"}

Com Grotowski, temos pudor de fazer perguntas ingênuas: filhas de ninguém a não ser do ingênuo desejo de entender. Por que pedir a Cieślak para relembrar o seu primeiro amor na adolescência, para trabalhar sobre um personagem nem adolescente nem apaixonado como Don Fernando? E por que depois transcender a revivescência daquela experiência com a ajuda do Cântico espiritual de João da Cruz? Graças às referências de ancoragem da "prece carnal", temos as respostas. Ao menos sabemos que nossas perguntas ingênuas foram a cobertura para uma outra, a verdadeira pergunta.

$\mathrm{Na}$ sua sala secreta, simplesmente, Grotowski e Cieślak tentaram recriar a situação de João da Cruz, "príncipe constante" antes e literalmente, que entrega ao Cântico espiritual o testemunho extremo do seu martírio. Porque ali estava o essencial sobre o arquétipo de Cristo: viver e sofrer o empenho da fé como um ato concreto de amor ${ }^{12}$. O resto - perseguidores, torturas, outros personagens foi a moldura na história real de João da Cruz, e agora era somente representação na história teatral de Don Fernando e Ryszard Cieślak. Bastava que o diretor cuidasse disso.

Cieślak foi chamado a encontrar as palavras físicas do seu Cântico na revivescência do primeiro encontro com o amor; a "leitura" do Cântico, de João da Cruz, serviu para acender aquela revivescência até sublimá-la, transcendê-la em uma "prece carnal". Como aconteceu no antecedente histórico, no cárcere de Toledo.

Sim, mas como? É com esta pergunta que começa a outra metade da viagem.

\footnotetext{
${ }^{12}$ É o caso de ressaltar que o arquétipo não coincide com o modelo utilizado a cada vez para evocá-lo. Para ficar no nosso âmbito, Kordian e Don Fernando são ambos modelos que, através dos seus suportes narrativos, consentem a evocação do mesmo arquétipo cristológico.
} 
Até o ponto, em três etapas

Até o ponto de ter que colocá-la, chegamos, fundamentalmente, em três etapas. Na primeira, concluída com o "Programa" do espetáculo, apuramos que o "desenvolvimento do método" - a virada do Príncipe constante - consistia na superação de Stanislávski: da revivescência para trazer de novo à vida uma experiência pessoal à mesma revivescência, mas para dar voz e corpo a uma experiência universal. A agonia de um comandante caído em batalha, transcendida no sonho de uma morte heróica, para além da morte daquele certo, ou de qualquer outro, comandante, nas palavras de Flaszen, em Sobre o método de atuação. Com a segunda etapa, concluída com o último testemunho de Grotowski sobre o Príncipe constante, aprendemos que, para sair da metáfora, a "prece carnal" teve que se ancorar na leitura do Cântico espiritual, de João da Cruz. Uma árida nota bibliográfica, mas que de fato escancarava um mundo. A última etapa consistiu na imersão naquele mundo, até a revelação do Cântico espiritual e de João da Cruz para além dos seus estatutos formais de obra e autor.

O confronto de Grotowski e Cieślak com uma identidade como aquela foi a essência do saldo da metade da viagem. E agora, como? Através da técnica espiritual, responde Grotowski - para repropor de outra forma a mesma pergunta. Técnica espiritual, ou seja?

Os correspondentes naquelas cartas escritas entre 63 e 65 - citadas anteriormente - eram dois cultores apaixonados do hinduísmo: Lama e Kim, ou Ramakrishna e Vivekananda na onomástica dos seus acesos diálogos de Opole, para os quais, para além da Índia geográfica, existiam as "Índias de Nagarjuna e dos Tantra"13. De fato, Grotowski fala de bhakti e Hațha Yoga e em suma de todo "o patanjali do teatro" - onde, para despistar a censura, o mítico autor dos Yoga Sūtras, síntese de toda a sabedoria indiana sobre o argumento, é reduzido ao

\footnotetext{
${ }^{13}$ De acordo com as notas de Eugenio Barba (1998, p. 140) à carta de 10 de julho de 1963: Nagarjuna, que viveu entorno ao ano $150 \mathrm{~d}$. C., foi um monge budista cuja doutrina girava entorno do conceito de Sunnyatā, o Vazio; os Tantra são técnicas rituais do hinduísmo, ligadas à transmutação das energias do nível físico ao espiritual.
} 
anonimato. Difícil, senão impossível, encontrar referências concretas à "técnica espiritual". Grotowski fala explicitamente sobre isso duas vezes, no início da correspondência - em 15 e 21 de setembro de 1963 -, como de uma verdadeira iniciação cujos efeitos se revelam "no próprio organismo, na própria individualidade, concreta e cotidiana" (GROTOWSKI apud BARBA, 1998, p. 148). Entre as práticas eficazes para atingir o objetivo, destaca a "psico-análise do não privado", ainda que seja pela ressonância "ocidental" da expressão, que legitima a tentativa de compreender, sem que tenhamos, nós também, que nos adentrar nos orientes de Nagarjuna. Qualquer que seja a referência científica, aquele "não privado" indica um uso da introspecção psicanalítica para além dos confins do privado, uma evidente analogia com a revivescência para além de Stanislávski.

Grotowski (2016d, p. 20) retorna a este argumento em um texto de 65, intitulado L'attore denudato (O ator desnudado). A propósito da "função interhumana do excesso", eixo declarado da técnica espiritual, escreve:

De qualquer modo, esta qualidade do ator, uma qualidade absolutamente basilar, requer exercícios de caráter especial: tenho em mente exercícios de concentração. Concentração que não tem nada a ver com o narcisismo, com deliciar-se com as próprias experiências; em resumo, que não converge para aquilo que podemos chamar de "eu", mas para o que se pode definir como "Tu".

A passagem do privado ao não privado é declinada como passagem do "eu" ao "Tu", e o exercício psicanalítico do não privado como "exercícios especiais de concentração".

Sem entrar nos detalhes, para os quais remetemos à nota de rodapé, Grotowski extraiu $O$ ator desnudado da entrevista concedida a Barba intitulada /I nuovo testamento del teatro ( $\mathrm{O}$ novo testamento do teatro), eliminando as perguntas e introduzindo algumas variações ${ }^{14}$. As datas são importantes. $O$ novo

\footnotetext{
${ }^{14}$ Após o sucesso do Príncipe constante, foi solicitado a Grotowski um artigo sobre a sua concepção do teatro e do ator. Como foi dito, Grotowski o extraiu da entrevista II nuovo testamento del teatro, concedida a Barba, que está publicada no livro Per un teatro povero (GROTOWSKI, 1970). Uma vez que não foi publicada uma edição deste texto em polonês, o texto que circulou em sua pátria foi a "versão" l'attore denudato. O título remete explicitamente a João da Cruz, como salientou Ludwik Flaszen, em 94, acrescentando que "os escritos de São João da Cruz [foram] uma leitura muito importante no nosso grupo
} 
testamento é de 64, antes do Príncipe constante, fase "método"; 0 ator desnudado sai em setembro de 65, depois do Príncipe constante, fase "desenvolvimento do método": as variações introduzidas só podem se referir ao trabalho para o espetáculo. Pois bem, a passagem citada está ausente no texto originário de 64 , onde, ao contrário, os exercícios de concentração são declaradamente utilizados em uma perspectiva psicanalítica do "eu", ainda que seja com o objetivo de forçar a barreira do recalque ${ }^{15}$.

Em conclusão: os exercícios especiais de concentração em direção ao "Tu" sinalizam a passagem da psicoanálise do privado ao não privado e, além disso, indicam o caminho para superar a dimensão individual da revivescência segundo Stanislávski. A chave da mudança está em entender o "trabalho com Grotowski sobre as ações físicas" como exercício de concentração, mas é só uma questão de palavras.

Um confronto, entre tantos outros, com o livro de Thomas Richards sobre o argumento. Richards se refere ao trabalho com um aluno aspirante sobre uma acting proposition baseada na lembrança do pai que volta para casa bêbado e cai no chão enquanto canta uma canção.

Tentava lembrar, antes de tudo, o comportamento físico naquelas circunstâncias - escreve Richards. Havia entrado em casa. Como caminhava? Era pesado. De que maneira era pesado? Onde olhava? Olhava para o chão. Onde estava situado o peso do seu corpo? Qual era a canção que estava cantando? Qual era a qualidade sonora do seu canto? Em qual ressonador do corpo estava colocada a sua voz, e porque? Porque tinha se embebedado? (RICHARDS, 1993, p. 86-87)

É Richards que conduz, imaginem quando a fazê-lo fosse Grotowski em pessoa. As perguntas contínuas, prementes, na busca implacável de uma sempre maior precisão, podem muito bem ser definidas como um "exercício de concentração". Física - não em vez de, mas sim além de mental. O problema é

e influíram seriamente no trabalho de Cieślak no Príncipe constante" (FLASZEN apud OSIŃSKI, 2011, p. 242).

${ }^{15}$ A passagem interpolada remete ao livro de Barba (1965, p. 94-95) Alla ricerca del teatro perduto, onde se fala de exercícios de concentração, mas com o objetivo de "encontrar como que os slogans, as fórmulas entorno das quais se dispõe todo um casulo de reações instintivas ligadas à sua particular personalidade [grifo meu]: por exemplo: 'sou feio', 'ninguém me ama'”. 
outro e é duplo: primeiro, até que ponto levar o exercício e, segundo, em qual direção. Para além de Stanislávski, a direção só pode ser o "Tu". Não mais na direção de Cieślak e da sua namorada, ou na direção de outros "tu" adolescentes e outros primeiros amores, mas em direção ao problema do Amor.

Para Grotowski e Cieślak, na sua sala secreta, foi o problema do Amor, maiúsculo e universal. O Cântico espiritual de João da Cruz indicou em qual direção levar aquela revivescência. Mas: o que acontece no ator em revivescência quando é superada a fronteira entre "eu" e "Tu" e, ainda por cima, quando a superação é levada adiante com toda a maestria e a intransigência de um Grotowski?

\section{Um exercício de concentração}

Eis que o adolescente relembrado chegou ao culmine da liturgia do cortejo, ele e a amada estão a ponto de unirem-se, dois em um, se tocam, se afastam, se reaproximam, entrando em um bosque fechado, procurando um lugar que não seja para ninguém além deles. Param, se olham, ele a olha. Como? De longe ou se aproximando? Endereçando o olhar para que parte do corpo? Para o rosto ou para os olhos dela? Que foge do olhar? Ou o acolhe e retribui? E assim, ainda outras perguntas e outras respostas, em um incansável exercício de concentração sobre aquele olhar - até que ele e ela torne-se tu e eu na experiência vivida, tu e $\mathrm{eu}$

Cheguemos a nos ver em tua beleza; ou seja, sejamos semelhantes em beleza, e que tua beleza seja tal que olhandonos um ao outro, cada um de nós se pareça a ti em tua beleza e se veja em tua beleza; isso acontecerá transformando-me em tua beleza. E assim, verei a ti em tua beleza; e tu te verás em mim em tua beleza, e eu me verei em ti em tua beleza; e assim eu me pareça contigo em tua beleza, e tu pareças comigo em tua beleza, e minha beleza seja tua beleza e tua beleza minha beleza, e eu serei tu em tua beleza e tu serás eu em tua beleza, porque tua própria beleza será minha beleza ${ }^{16}$. (DE LA CRUZ

\footnotetext{
16“lleguemos a vernos en tu hermosura; esto es, que seamos semejantes en hermosura, y sea tu hermosura de manera que, mirando el uno al otro, se parezca a ti en tu hermosura, y se vea en tu
} 
apud DE JESUS O. C. D.; DEL NIÑO JESUS O. C. D.; RUANO

O. C. D., 1978, p. 834)

Não sabemos, evidentemente, se Grotowski conhecia e, no caso afirmativo, tenha usado essas palavras de João da Cruz no seu "trabalho sobre as ações físicas". E não sabemos nem mesmo se, para a leitura em comum com Cieślak, tenha usado uma edição que incluísse essas palavras. Fazem parte do comentário ao verso "y vámonos a ver en tu hermosura", da estrofe 35 , que integralmente recita:

Gocémonos, Amado, y vámonos a ver en tu hermosura al monte $o$ al collado, do mana el agua pura; entremos más adentro en la espesura ${ }^{17}$

Mas não importa, realmente não importa. A referência ao comentário de João da Cruz está aqui para mostrar que aquelas explicações para uso da madre superiora não explicam, com certeza, de onde vêm os versos do Cântico, mas indicam onde e até onde possam levar, quando são assumidos como veículo. Não explicam como o espírito se fez carne, na prisão de Toledo; e porém, indicam como e até que ponto a carne daqueles versos possa se refazer espírito. Naquilo que João da Cruz chama de "exercícios de beleza", teologia, lógica, mística ou literatura cedem o passo ao ritmo puro, que é fôlego, respiração, pulsação: sístole e diástole, tu e eu, a tua beleza como espelho da minha e a minha como a imagem da tua beleza, aqueles olhares que se remetem um ao outro, porque é um único olhar a partir e a retornar, voltar e ir outra vez, até produzir, mesmo em uma leitura fria, a vertigem de um orgasmo. E não há como evitar a palavra, mas sem banalizá-la: a experiência do êxtase.

hermosura, lo qual será transformándome a mí en tu hermosura; y así te veré yo a ti en tu hermosura; y tú te verás en mí en tu hermosura, y yo me veré en ti en tu hermosura; y así parezca yo tú en tu hermosura, y parezcas tú yo en tu hermosura, y mi hermosura sea tu hermosura, y tu hermosura mi hermosura, y seré yo tú en tu hermosura, y serás tú yo en tu hermosura, porque tu hermosura misma será mi hermosura" (nota do tradutor: original espanhol reportado em nota de rodapé no original).

17 Gozemo-nos, Amado, / e vamo-nos ver em tua beleza / no monte ou na colina, / de onde brota a água pura; / entremos mais adentro na espessura (nota do tradutor: em espanhol no original). 
O exercício de concentração, ao realizar a separação do "eu", chegou ao "Tu", onde o namorado e a namorada adolescentes são a Alma e Cristo, a esposa e o esposo - e o amor deles no denso bosque é a união mística em Deus. Se tocam, enfim, o João da Cruz, renascido do próprio colapso, que escreve o Cântico espiritual, e Cieślak renascido por "especial exercício de concentração" que escreve, com as palavras físicas da própria revivescência, a mesma prece carnal.

\section{Retomar a viagem. 0 "depois"}

E, deste modo, poderíamos dizer que a viagem está concluída. Se deve ser retomada - e deve - é apenas para encarar a pergunta: o que resta do segredo do Príncipe constante quando não há mais o Príncipe constante?

Usando fórmulas não é difícil arriscar uma resposta, e provavelmente não se acertaria muito distante do alvo. Olhando a partir da "arte como veículo", poderíamos reconhecer: na revivescência amorosa de Cieślak, um caso particular de veículo; na prece carnal, uma ocorrência de higher connection; e nos exercícios especiais de concentração, um antecedente "não objetivo" daquelas práticas objetivas descobertas no Teatro das Fontes. Acontece, porém, que as fórmulas funcionam bem em projeções de longo alcance, aonde as pessoas atingem, com o tempo, o anonimato que pertence às fórmulas por direito de identidade.

Mas, antes, quando as pessoas ainda não se tornaram fórmulas, o que se teria visto logo depois do Príncipe constante?

\section{Holstebro-1971}

Logo depois é 1971. Em dezembro de 1970, em Berlim, aconteceu a última apresentação do Príncipe constante, e poucos dias depois, em Nova York, Grotowski havia oficializado urbi et orbi o abandono do teatro dos espetáculos. 
Apocalypsis cum figuris, o último fruto da sua teatrografia, já havia se convertido em uma barca para a travessia - de atores e espectadores - para além do espetáculo. Não mais o Príncipe constante e não mais espetáculos a serem feitos, em 1971. E havia Grotowski, enfim, transfigurado, depois da sua terceira viagem à Índia, no verão de 1970, a tal ponto que os próprios atores do Teatro Laboratório custaram a reconhecê-lo no aeroporto de Shiraz. Além dos muitos quilos a menos, era toda a sua aparência: o rosto agora coberto por uma barba rala e desgrenhada, os cabelos despenteados, as lentes e o feitio dos óculos, a roupa de hippie. Conta-se que em Nova York, o agente americano teve que garantir formalmente que o personagem ali presente era o mesmo Grotowski que, a pouco mais de um ano atrás, espectadores e críticos haviam aclamado como o diretor do extraordinário tríptico com Akropolis, Príncipe constante e Apocalypsis cum figuris. Quando apresentadas como caricaturas, as anedotas terminam por deixar mais evidente a realidade: 1971 era logo depois de tudo.

Mas o ano de que falo é acompanhado de coordenadas de lugar e de circunstância. É um certo 1971. É Hosltebro-1971. Por ocasião de um dos seus seminários internacionais, naquele particular 1971, o Odin Teatret hospedou o último espetáculo do Teatro Laboratório, junto com Grotowski e Cieślak com seu personagem e seu treinamento.

Além de nos Anais do Odin, Holstebro-1971 deixou vestígios em dois filmes, relativos aos dois protagonistas do Príncipe constante. Nada de memorável, ao contrário. Foram, antes, como as proverbiais garrafas lançadas ao mar, que depois terminam na praia. Insignificantes detritos da maré, se não fosse pela mensagem que às vezes encontramos dentro delas.

\section{O bueiro e o esgoto}

O vídeo de Cieślak é muito conhecido, falarei sobre ele em breve. O vídeo de Grotowski, por outro lado, muito menos famoso, é clandestino ou talvez pirata, segundo Eugenio Barba. Seu título é Grotowski at Odin Teatret. Holstebro, 1971. O que segue é, por extenso, a mensagem que eu encontrei dentro dele. 
Em 21 de setembro de 1963, Grotowski havia escrito a Barba:

O senhor escreveu dizendo que desejaria ver os resultados concretos do seu trabalho. Pois bem, permita-me que lhe diga: resultados concretos não se veem nunca. Os resultados concretos (sobretudo em uma arte fugaz como o teatro) nascem e morrem num abrir e fechar de olhos, e penso que seja errado ligar-se a eles. Acredite em mim, tenho o direito moral de falarIhe desta maneira. Possui-se de verdade somente aquilo de que se fez experiência, sendo assim (no teatro), aquilo que se sabe e que se pode ser verificado no próprio organismo, na própria individualidade concreta e cotidiana. É exatamente aqui que se encontra a semente de nossas últimas investigações: o artesanato (direção? arte do teatro?) construído e experimentado no próprio organismo vivente que, com relativa certeza, nos acompanha. (GROTOWSKI apud BARBA, 1998, p. 147-148, grifo do autor)

Até mesmo "direito moral". Mas, a pergunta tocava uma questão fundamental: o cerne da eficácia do teatro. Stanislávski a colocou há tempos - e para sempre - em termos de "trabalho do ator" e "trabalho sobre si mesmo", atribuindo ao diretor - entre as opções extremas do ensinamento e da iniciação a decisão sobre como as fazer conviver, ou se adotar uma delas e excluir totalmente a outra. Lido sem simplificações ou sofismas de "sistema", O trabalho do ator sobre si mesmo propõe todo o espectro das possibilidades: de um trabalho a ser usado exclusivamente na cena até um outro - ao contrário - em função apenas da dimensão íntima do "Si".

Falavam entre profissionais, no entanto, poucas linhas antes do "direito moral", Grotowski havia proposto a Barba de "iniciá-lo, na prática, [neste] conhecimento absolutamente concreto que pode ser estudado e verificado no próprio organismo" (Ibidem, p. 147, grifo do autor). O havia proposto também uma semana antes, especificando que a "iniciação" seria "prática e individual" (Ibidem, p. 143). Não sabemos em que termos Barba tivesse formulado a pergunta inicial, mas podemos imaginar a resposta que teria dado ao duplo convite de Grotowski.

Em uma entrevista concedida, em 2011, a Mirella Schino, fala da improvisação como caminho para a incandescência do ator. É um procedimento 
delicado - diz - que não pode nem deve se tornar uma técnica: é como ensinar um caminho secreto.

Depois que você o ensinou, diz "olha, eu te levo até aqui, onde tem a tampa do bueiro, você abre e pode descer, vai no esgoto, e nos esgotos de Paris estão os mistérios de tudo, mas você que tem que decidir!". Uma vez que você ensinou onde está o bueiro, como se abre e que você pode descer lá dentro, é o ator que tem que decidir ${ }^{18}$.

$\mathrm{O}$ bueiro e o esgoto. Tanto Barba quanto Grotowski sabem que a incandescência do ator requer o preço de uma imersão nos "esgotos de Paris". Mas, até o bueiro, vão juntos, depois se separam. Barba deixa que o ator decida por si mesmo, e ele fica do lado de fora; Grotowski desce antes, levando o ator atrás dele. Para Barba, o trabalho do ator é também trabalho sobre si, e é tarefa do ator decidir se e como fazê-lo - em primeira pessoa. Para Grotowski, o trabalho do ator era, ou se era revelado, essencialmente trabalho sobre si, e era tarefa do diretor e do ator fazê-lo juntos - como uma pessoa dupla.

Desceu junto com Cieślak, Grotowski, no trabalho secreto para o Príncipe constante, e juntos viajaram através dos esgotos de Paris, onde "estão os mistérios de tudo". Quanto tempo durou a viagem? "Meses e meses", dirá diversas vezes Grotowski, com a repetição que desloca o acento da quantidade à continuidade da duração. E naqueles meses, ou que fossem semanas, por dias e dias, ou até mesmo por horas e horas, na implacável busca da precisão - quando não se busca mais a precisão, fatalmente se encontra a repetição, a revivescência morre - nas ações, nas emoções e nos pensamentos, e também naquele estado do ser que está além da ação e da emoção e do pensamento; assim como advertia, como um baixo contínuo, a voz de João da Cruz no Cântico espiritual. Alguma coisa acontece, não pode não acontecer, e - justamente como dizia Grotowski - mais que no resultado artístico, "no próprio organismo, na própria concreta e cotidiana individualidade". Algo acontece, e sem distinção entre um viajante e o outro, entre o ator e o diretor.

${ }^{18} \mathrm{O}$ texto da entrevista é inédito. Pude consultá-lo devido à gentil concessão de Mirella Schino, a quem agradeço. 
Assim se conclui aquele diário de bordo da viagem secreta que é o ensaio Per un teatro povero (Para um teatro pobre):

No trabalho do ator é possível o fenômeno particular de um "nascimento" a dois. Então, o ator nasce, de novo, não apenas no âmbito do artesanato, mas ainda mais enquanto pessoa. Ao lado do seu novo "nascimento" coloca-se, a cada vez, o novo "nascimento" daquele que guia a ação. (GROTOWSKI, 2016e, p. 34)

Como sempre, a melhor maneira de entender as palavras de Grotowski e tomá-las ao pé da letra.

É um estranho filme, Grotowski at Odin Teatret, Holstebro $1971^{19}$. É mudo. Por cerca de nove minutos dos seus nove minutos e meio de duração, apresenta cenas de conversação entre os participantes do seminário, na biblioteca-foyer do Odin. Entre os vários personagens, destacam-se um Barba sempre ofegante e um Grotowski muito magro e com a camisa aberta até o último botão, seguindo rigorosamente a normativa hippie.

Resta aquele pouco mais de meio minuto. É composto por dois fragmentos, ambos com Grotowski en plein air - nu, salvo por uma tanga branca e volumosa, nem cueca nem sunga, pelo que se pode ver -, lutando com uma coberta que se rebela devido às rajadas de vento adversas. Um dos fragmentos está no início, o outro no fim, ambos sem nenhuma razão de ordem narrativa. Uma moldura, uma guia à visão.

Uma mensagem na garrafa. Como se na aparição do duplo de Cieślak príncipe constante se revelasse o Grotowski renascido: a "sub-stantia" daquele

\footnotetext{
${ }^{19}$ Não se trata de um filme clandestino, ou mesmo pirata. O DVD circula com a marca conjunta "Odin Teatret Film" e CTLS "Centre for Theatre Laboratory Studies", logo de forma absolutamente oficial. Se algo de clandestino pode ser entrevisto está na falta de títulos no início ou no fim, que informem sobre os autores. Podemos presumir, em todo caso, que a direção fosse de Torgeir Wethal.
} 
personagem de camisa desabotoada no espaço fechado da biblioteca, conhecido publicamente como Jerzy Grotowski.

\section{Cieślak Príncipe Constante}

O outro filme de Holstebro-1971 se intitula Treinamento no Teatro Laboratório de Wrocław (demonstração de Ryszard Cieślak), 1972. É um dos vídeos de referência para os atores militantes na galáxia do assim chamado Terceiro Teatro ${ }^{20}$. E todavia, na sua precisão analítica, o título nos desvia do caminho. A mensagem dentro da garrafa não é aquela da etiqueta.

"Não era assim que os atores treinavam, no início", comenta Barba, na já citada entrevista com Mirella Schino (Cf. nota 18). O treinamento registrado no filme, continua, é apresentado somente por Cieślak, mas "Cielslak tinha passado pela 'barreira do som' do Príncipe constante" e, consequentemente, "havia toda uma reverberação de psicotécnica, de energia física". Na forma de exercício, emergiam materiais - talvez até mesmo fragmentos - do espetáculo. Algumas passagens, onde o decalque era evidente demais, tiveram que ser eliminadas na montagem final.

Não somente havia trazido para si a representação do treinamento de todos os atores. O havia feito cancelando o seu próprio passado - e o deles. Havia recomeçado a partir do espetáculo da "barreira do som". Ou melhor, da experiência que o havia transmutado de Cieślak, ator do Príncipe constante, em Cieślak príncipe constante. Sem que existisse mais a distância entre fora e dentro da cena - e do corpo - do personagem.

${ }^{20} \mathrm{O}$ filme foi realizado pelo Odin Teatret Filmarkiv, por iniciativa dos Programmi Sperimentali - Serie didattica (Programas experimentais - Série didática) da RAI (rede de televisão estatal italiana). Foi filmado em Wrocław, com direção de Torgeir Wethal e participação, como alunos, de Malou Illmoni e Tage Larsen, ambos na época, e Larsen ainda hoje, atores do Odin. 


\section{E depois}

O haviam deixado para trás, em Holstebro-1971, mas o Príncipe constante estava grudado nas costas dos dois - Cieślak e Grotowski - como um fardo ou um legado, ou mais simplesmente como um par de asas, que ainda serviam para se levantar da terra, mas não mais para voar. Na terra, havia o campo base do espetáculo; liberados no ar, aquela base não existia mais. O que estava em seu lugar? E já havia algo? Aqui, os caminhos se dividem. Se dividem os destinos de Grotowski e Cieślak.

Foi Grotowski que usou a imagem do voo para descrever o itinerário da própria pesquisa. Fora de toda retórica, era a referência que the servia para distinguir o estar no ar, que não vai a lugar nenhum, do estar em voo, que vê aonde ir e sabe como ir até lá. A ocasião foi a lectio magistrais para a laurea ad honorem que Ihe foi conferida em 1991 pela Universidade de Wrocław. Para mim, disse, existiram

dois cosmódromos. De um eu decolei e no outro eu pousei. A plataforma de lançamento foi a arte do teatro, aquela que eu chamo de arte como apresentação - a arte dos espetáculos, o teatro que constrói espetáculos - eis a minha pista de decolagem. É a base, o fundamento que me ensinou como é indispensável um artesanato sério e consistente. Mas depois, como se meu voo seguisse a trajetória de um raio, atravessei uma esfera de experiências singulares, onde o ar é mais rarefeito [...] era a trajetória das experiências, não da profissão, e a percorri para aterrisar no cosmódromo que é o meu campo de ação hoje e que chamo arte como veículo. A arte como veículo exige a mesma solidez artesanal da arte como apresentação. (GROTOWSKI, 2016f, p. 105) ${ }^{21}$

Decolagem, travessia ou aterrisagem, o motor do voo - diz Grotowski - é o "artesanato sério e consistente". Onde estão "experiências e não profissão", o ar se torna rarefeito, o motor não tem tração e é difícil voar, fica-se parado no ar. A não ser que exista um "raio" - um destino que indique e dê propulsão à rota. Não estava, então, tão longe do alvo a nossa projeção inicial por meio de fórmulas.

${ }^{21}$ Cf. também DEGLER, 2005. 
Era já a arte como veículo o objetivo em direção ao qual Grotowski orientava o voo. Para além dos baixios aéreos das experiências singulares, ou, na definição lapidária e sulfúrea de Ludwik Flaszen, do "Não-teatro no estado selvagem" (FLASZEN, 2001b, p. 29).

E Cieślak, tinha Cieślak um destino capaz de desencalhá-lo das experiências sem profissão, e the dar uma profissão ou, como para Grotowski, fazê-lo recuperá-la das origens do teatro dos espetáculos?

Escreve Ferdinando Taviani que, ao seguir Grotowski para além dos confins do teatro-espetáculo, Cieślak não fez concessões. Simplesmente "transformou a sua presença de ator naquela de um stalker" (TAVIANI, 1991, p. 180) ${ }^{22}$. Na concepção que o termo assumiu com o filme de Tarkovski, stalker é o guia que conhece todos os meandros da "zona", e sabe conduzir o Escritor e o Professor do filme - os personagens que a estão procurando - até a "sala misteriosa", onde é possível realizar os desejos mais secretos, inclusive aqueles que à luz da consciência se teria medo de ver realizados. Depois do Príncipe constante, Cieślak poderia se dizer um stalker. Mas, sobre o stalker-ator pesa a hipoteca do ator, que para mostrar deve mostrar-se. E se ainda por cima o ator é o ator-deGrotowski, mostrar-se na recusa total, orgânica, da mentira.

Eugenio Barba recorda quando Cieślak, em julho de 1966, em Holstebro, depois de ter se proposto em fevereiro como o protagonista do lendário espetáculo, conduzia sessões de treinamento.

Cieślak - escreve - era incansável, exortava os participantes a superar os próprios limites, a ultrapassar as fronteiras das próprias possibilidades, incitava-os mesmo se estivessem extenuados. Ele mesmo dava o exemplo dedicando-se ao máximo a cada um dos participantes [...] Cada vez mais, porém, emergiam as características do "príncipe constante". Muitas vezes me perguntei se aquele papel o aprisionasse ou se, ao contrário, o tivesse feito descobrir sua identidade íntima, presente então em cada ação. (BARBA, 1998, p. 116)

\footnotetext{
${ }^{22} \mathrm{O}$ texto foi reproposto em francês no citado volume em homenagem a Cieślak, organizado por George Banu, Cieślak pour memoire e, enfim, republicado em inglês como Memory of Ryszard Cieślak, em The Grotowski Sourcebook.
} 
A "sala misteriosa" que o stalker-Cieślak podia mostrar aos que a buscavam era o próprio organismo de ator - agora confundido - ou aprisionado - naquele do príncipe constante.

Um episódio pouco conhecido, para concluir, entre 25 de março e 3 de abril de 1976, em Paris, Cieślak se submeteu a um teste diante de Peter Brook e Madame Jeanne de Salzmann. Brook tinha a intenção de confiar a ele o papel de Gurdjieff adulto, no filme Encontros com homens notáveis. Não se fez nada. Quem decretou a exclusão do candidato foi madame de Salzmann. Simplesmente, Cieślak não tinha conseguido caminhar ereto, com a cabeça em vertical sobre os ombros.

Cabeça em vertical sobre os ombros: difícil encontrá-lo nesta posição no vídeo sobre o treinamento de 72 , ou ainda mais naquele do espetáculo. Mais que ser incapaz, talvez, Cieślak não tenha querido assumir aquela postura de ser humano normal. Carcereiro ou íntimo duplo, o príncipe constante já tinha se tornado o seu destino ${ }^{23}$.

Cieślak morreu em 15 de junho de 1990, devido a um câncer nos pulmões. A algum tempo, fumava e bebia além da medida, preparava a própria morte. Em 9 de dezembro, no Odéon, em Paris, foi organizada uma noite em sua memória. Nos Anais, estão reunidas as intervenções dos pesquisadores presentes, a nata dos admiradores, inútil listar os nomes.

Além de oficinas e estágios em vários grupos e instituições, Cieślak havia realizado - a partir de Thanatos Polski, de 1981 - numerosos não-espetáculos, como os chamava; e no Mahabharata de Brook foi, entre 1985 e 1988, o rei cego Dhritarashtra. Uma lista de realizações de respeito. Apesar disso, todos os participantes na homenagem, começando por Grotowski, diretamente ou indo chegar lá, falam do Príncipe constante, não de outra coisa. Como se, enquanto a

\footnotetext{
${ }^{23}$ Sobre este episódio, cf. DI DONATO, 2009.
} 
biografia seguia o seu curso com os eventos que se sucediam, o destino - onde tudo já aconteceu - tivesse se cumprido no distante 1965.

Para Cieślak, com certeza. Para Grotowski? Quando a viagem acaba parece que não tem mais nada. Ao invés disso, falta ainda o essencial, o retorno. Ao retorno, nada mais é como víamos no início. Tudo é mais complexo, ou seja, mais simples. Daí, a viagem deveria recomeçar.

Recebido em: 26/08/2019

Aceito em: 30/10/2019

\section{Referências}

BARBA, Eugenio. La terra di cenere e diamanti: il mio apprendistato in Polonia. Bologna: II Mulino, 1998.

BARBA, Eugenio. La zona torrida del ricordo. In: Bruciare la casa: origini di un regista. Milano: Ubulibri, 2009.

BARBA, Eugenio. Alla ricerca del teatro perduto. Padova: Marsiglio, 1965.

DEGLER, Janusz. Laudatio. In: DEGLER, Janusz e ZIOLKOWSKI, Grzegorz (org.). Essere un uomo totale. Corazzano: Titivillus, 2005.

DE JESUS O. C. D., Crisogono; DEL NIÑO JESUS O. C. D., Matias; RUANO O. C. D., Licino. Vida y obras de San Juan de la Cruz. Madrid: Biblioteca de Autores Cristianos, 1978.

DI DONATO, Carla. Un provino per Cieślak (parigi 1976) - Nota sul personaggio di Gurdjieff per il film di Brook "incontri con uomini straordinari". In: Teatro e Storia, n.s. 1, 2009.

FLASZEN, Ludwik. Amleto nel laboratorio teatrale. In: FLASZEN, Ludwik e POLLASTRELLI, Carla (org., con la collaborazione di Renata Molinari). Teatr Laboratorium di Jerzy Grotowski 1959-1969. Pontedera: Fondazione Pontedera Teatro, 2001a.

FLASZEN, Ludwik. Da mistero a mistero: alcune osservazioni in apertura. In: FLASZEN, Ludwik e POLLASTRELLI, Carla (org., con la collaborazione di Renata Molinari). Teatr Laboratorium di Jerzy Grotowski 1959-1969. Pontedera: Fondazione Pontedera Teatro, 2001b. 
FLASZEN, Ludwik. L'arte dell'attore. In: FLASZEN, Ludwik e POLLASTRELLI, Carla (org., con la collaborazione di Renata Molinari). Teatr Laboratorium di Jerzy Grotowski 1959-1969. Pontedera: Fondazione Pontedera Teatro, 2001c.

FLASZEN, Ludwik. Metodo per l'arte dell'attore. In: FLASZEN, Ludwik. Grotowski \& Company: Sorgenti e variazioni. Organização Franco Perrelli. Bari: Edizioni di pagina, 2014.

GROTOWSKI, Jerzy. Per un teatro povero. Roma: Bulzoni, 1970.

GROTOWSKI, Jerzy. Dalla compagnia teatrale all'arte come veicolo. In: RICHARDS, Thomas. Al lavoro con Grotowski sulle azioni fisiche. Firenze: La Casa Usher, 1993 (p. 123-141).

GROTOWSKI, Jerzy. Le Prince Constant de Ryszard Cieślak. In: BANU, George (org.). Ryszard Cieślak, acteur-emblème des années soixante. Paris: Actes Sud, 1992.

GROTOWSKI, Jerzy. Risposta a Stanislavskij. In: GROTOWSKI, Jerzy. Testi 1954-1998 - Vol. II: II teatro Povero. Organização e tradução Carla Pollastrelli. Firenze: La Casa Usher, 2016a (p. 231-244).

GROTOWSKI, Jerzy. Dalla compagnia teatrale all'arte come veicolo. In: GROTOWSKI, Jerzy. Testi 1954-1998 - Vol. IV: L'arte come veicolo. Organização e tradução Carla Pollastrelli. Firenze: La Casa Usher, 2016b (p. 75-91).

GROTOWSKI, Jerzy. II Principe costante di Ryszard Cieślak. In: GROTOWSKI, Jerzy. Testi 1954-1998 - Vol. IV: L'arte come veicolo. Organização e tradução Carla Pollastrelli. Firenze: La Casa Usher, 2016c (p. 92-99).

GROTOWSKI, Jerzy. L'attore denudato. In: GROTOWSKI, Jerzy. Testi 1954-1998 - Vol. II: Il teatro povero. Organização e tradução Carla Pollastrelli. Firenze: La Casa Usher, 2016d (p. 17-24).

GROTOWSKI, Jerzy. Per un teatro povero. In: GROTOWSKI, Jerzy. Testi 19541998 - Vol. II: Il teatro Povero. Organização e tradução Carla Pollastrelli. Firenze: La Casa Usher, 2016e (p. 25-34).

GROTOWSKI, Jerzy. Discurso in occasione del conferimento della laurea honoris causa. In: GROTOWSKI, Jerzy. Testi 1954-1998 - Vol. IV: L'arte come veicolo. Organização e tradução Carla Pollastrelli. Firenze: La Casa Usher, $2016 f$ (p. 100108).

MANGO, Lorenzo. II Principe costante di Calderón de la Barca-Słowacki, per Jerzy Grotowski. Pisa: ETS, 2008. 
OSIŃSKI, Zbigniew. Jerzy Grotowski e il suo laboratório: dagli spettacoli a L'arte come veicolo. Organização e tradução de Marina Fabbri. Roma: Bulzoni, 2011.

OUAKINE, Serge. Le Prince constant. Etude et reconstitution du déroulement du spectacle. In: AA. VV. Les voies de la création théâtrale, 1. Paris: CNRS, 1970.

RICHARDS, Thomas. Al lavoro con Grotowski sulle azioni fisiche. Firenze: La Casa Usher, 1993.

RICHARDS, Thomas. Trabalhar com Grotowski sobre as ações físicas. Tradução Patrícia Furtado de Mendonça. São Paulo: Perspectiva, 2012.

RUFFINI, Franco. Per un teatro povero. In: Grotowski e Gurdjieff. Napoli: Editoriale Cientifica, 2019 (p. 185-210).

TAVIANI, Ferdinando. Cieślak promemoria. In: Teatro e Storia, V. 10, aprile 1991 (p. 179-201).

Disponível

em:

http://www.teatroestoria.it/pdf/10/Ferdinando_Taviani_122.pdf. Consulta em: 13/2/2020. 